\title{
Paraclinical Investigations in the Pathology of the Urinary System in Dogs
}

Sabina GHERGARIU ${ }^{1}$, Mariana TĂTARU ${ }^{1 *}$, Michail DIAKOSAVVAS ${ }^{1}$, Loredana Elena OLAR ${ }^{1}$, Sorin Marian MÂRZA $^{1}$, Nicolae COLDEA ${ }^{1}$, Ionel PAPUC ${ }^{1}$

${ }^{1}$ Department of Semiology, Ethopathology and Medical Imaging, Faculty of Veterinary Medicine, University of Agricultural Sciences and Veterinary Medicine, Cluj-Napoca

*corresponding author: mariana.tataru@usamvcluj.ro

Bulletin UASVM Veterinary Medicine 75(2)/2018

Print ISSN 1843-5270; Electronic ISSN 1843-5378

doi:10.15835/buasvmcn-vm: 2018.0027

\begin{abstract}
:
In the pathology of the urinary system, given its structural and functional complexity, the clinician must correlate the data obtained from the clinical and paraclinical examination. The aim of the study was to identify and apply the most relevant paraclinical methods for establishing the diagnosis of renal disease in dogs and to develop a reliable and easy to use working protocol. The biological material consisted of 25 dogs of different ages and sexes. The conventional and contrast-enhanced radiological examination together with the ecography, spectrofluorimetric analysis, urinary sediment examination, renal biopsy, cytological examination completed the disease information in order to establish a certitude diagnosis. In the management of patients with urinary disorders, the working protocol should include not only the animal anamnesis and a complete clinical examination but also a paraclinical examination which should be used depending on the patient's clinical manifestations.
\end{abstract}

Keywords: dog, paraclinical examination, renal pathology, urine

\section{Introduction}

Most of the urinary system diseases can be diagnosed based on medical history, clinical examination, blood biochemistry, urine biochemistry and bacterial uroculture in the aerobic environment (Medaille and BriendMarchal, 2008). In patients with micturition problems, complete neurological examination should also be conducted (Merck Manual, 2014). The complementary tests frequently used in dog kidney disease are: full blood count, blood gas analysis for the evaluation of acid-base balance, blood pressure, urinary protein/creatinine ratio, iohexol clearance, control abdominal X-ray, abdominal ultrasound, urinary bladder cystoscopy and renal biopsy. An extremely useful paraclinical examination for the evaluation of the urinary tract is urinalysis (Herbert, 2006). Urine can be collected by spontaneous micturition, manual compression of the urinary bladder, catheterization and cystocentesis. Urine assessment should include: the collection method, osmolarity, color, turbidity, $\mathrm{pH}$, glucose, ketonic bodies, bilirubin (Icotest), and the presence of occult hemorrhage, protein, leukocytes. The microscopic examination of the urinary sediment will monitor the presence of cells (red blood, white blood, epithelial), urinary cylinders, bacteria, fungi, parasite eggs, lipids, spermatozoids (Lulich et al., 2016). The presence of protein in urine should be evaluated in relation to specific urine density.Urine dipsticks allow a semiquantitative evaluation of protein, being influenced by urine $\mathrm{pH}$. The use of dipsticks for the measurement of urine protein has a screening role, and in order to establish its concentration, the protein/creatinine ratio must be determined in a single urine sample or in a urine sample collected over 24 hours. Urinalysis cannot be used 
to exclude urinary tract infection, because not all infections are associated with inflammatory response (Muñoz et al., 2015).

In dogs, the radiological examination can beperformed through ascending urography or descending urography.In the case of ascending urography, the introduction of the contrast substance is made by bladder catheterization,on the other handin the case of descending urography, the intravenous route is preferred. Very good results with minimal risks can be obtained in urography if non-ionic contrast substances are used. The contrast substance can penetrate in the renal pelvis, which allows assessing its shape, size and integrity. Urinary excretion of the contrast substance ensures a verification of the urinary tract functionality regarding the propagation, permeability, filling and evacuation of the urinary bladder (Thrall and Robertson, 2010). By using theultrasound examination, structural changes in the renal parenchyma, topographical, dimensional and structural changes of the bladder, the existence of urinary bladder stones, the presence of diffuse tumor processes, solid or cystic tumors andthe presence of retroperitoneal masses can be evidenced (Barr and O'Brien, 2009; Froes et al., 2007; Hann et al., 1994; Hanson et al., 2001; Kealy, 2005; Sato and Solano, 2004; Schelling et al., 1988). Spectrofluorimetry is used to evidence urine fluorophores in patients with a suspicion of diabetes (Olar et al., 2018; Šteffeková et al., 2015; Yanagisawa et al., 1998). Serum biochemistry is used to determine blood urea, serum creatinine, calcium, phosphorus, bicarbonate and electrolytes. The method provides information about the glomerular filtration rate, but interpretation should be made with discernment because the increase of blood urea and creatinine can be induced by other causes that are not related to the kidneys. In addition to the mentioned constituents, alkaline phosphatase, serum transaminases, gamma-glutamyltransferase (GGT), cholesterol, bilirubin, ketonic bodies, triglycerides, albumin, total protein, total bilirubin, pancreatic lipase and alpha amylase were determined (Kaneko et al., 2008; Vaden et al., 2009). Fungal infections frequently affect the kidneys and prostate (Merck Manual, 2014).

The aim of our study was to identify and apply the most relevant paraclinical methods for establishing the diagnosis of urinary disease in dogs and to develop a reliable and easy to use working protocol.

\section{Materials and methods}

The study was conducted in 25 dogs of different ages and sexes, which were examined at the Internal Medicine, the Emergency Hospital and veterinary offices adjacent to the Faculty of Veterinary Medicine Cluj-Napoca, and were referred to the medical imaging service and the clinical laboratory.

In order to be included, dogs had to present one of the following clinical diagnoses: renal colic with hematuria; urinary retention; various injuries; chronic renal failure; suspicion of diabetes mellitus.

The working protocol was identical for all cases. Initially, general examination was performed, which was followed by examination of the abdomen and urinary system.

\section{Results and discussions}

After the clinical examination of the 25 patients included in the study, 7 patients representing 28\% of all patients were diagnosed with renal colic syndrome and hematuria, 3 patients representing $12 \%$ were diagnosed with urinary retention, 4 patients representing $16 \%$ suffered from various injuries that also affected the urinary system, 5 patients representing $20 \%$ had chronic renal failure, and 6 patients representing 24\% had clinical signs of diabetes mellitus. Of all the examined cases, 20 patients $(80 \%)$ were male and 5 patients $(20 \%)$ were female. The patients' age ranged between 5 and 7 years (Figure 1).

In order to establish adefinitive diagnosis, each patient was referred for other paraclinical investigations depending on the clinical diagnosis made.

The patients diagnosed with renal colic syndrome and hematuria clinically manifested pollakiuria, hematuria, dysuria and urination in inadequate places. Hematuria observed at the end of the urine jet oriented diagnosis towards urinary bladder infections. The differential diagnosis methods performed were urinalysis, which showed increased protein concentrations $(>0.5 \mathrm{~g} / \mathrm{L})$, alkaline $\mathrm{pH}(7.5-9)$, and in the urinary sediment, leukocytes, erythrocytes and bacteria were evidenced. In renal infections, the dominant clinical signs were the following: renal or flank 


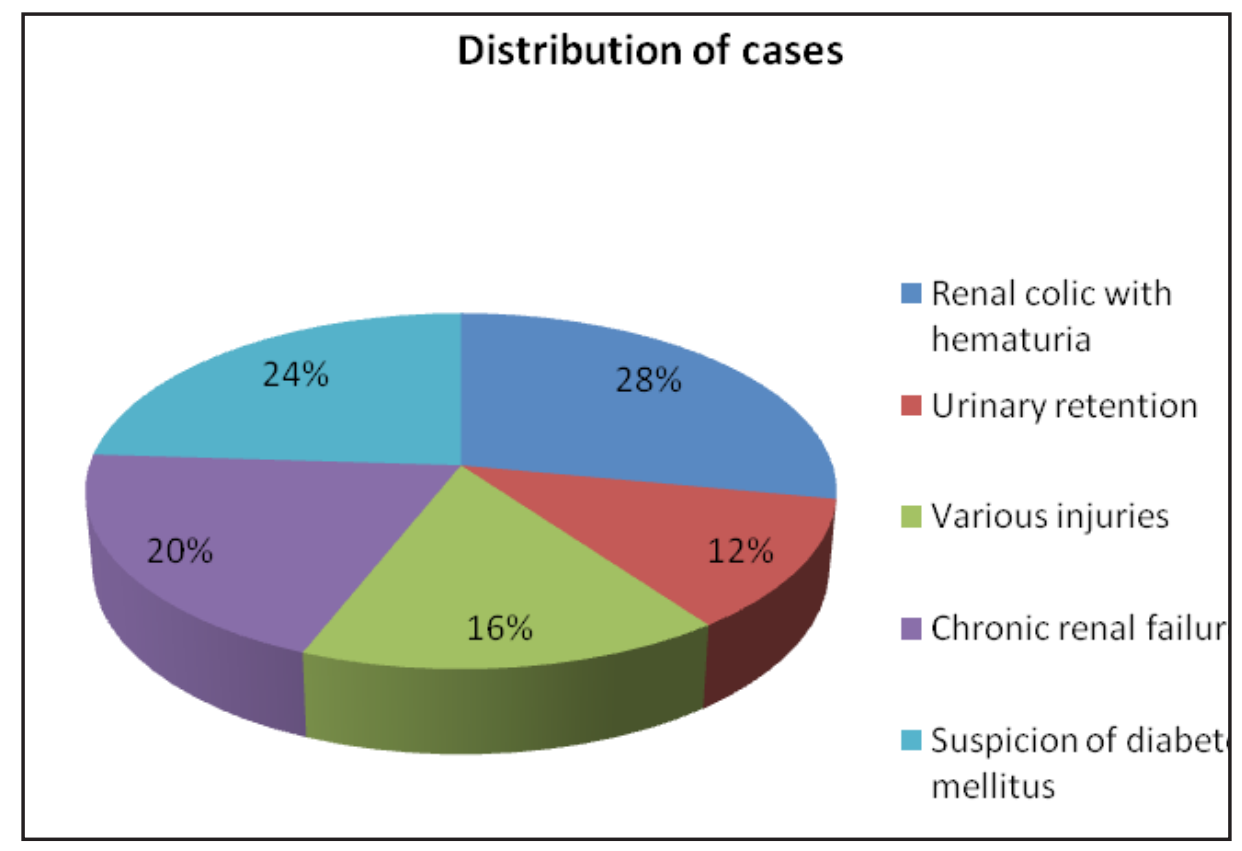

Figure 1. Distribution of cases depending on clinical diagnosis

pain, fever, sometimes vomiting, polydipsia, polyuria. Urinalysis detected: proteinuria, pyuria, bacteriuria or hematuria. Leukocyte cylinders were identified in the urinary sediment, and the biochemical profile revealed azotemia or hyperglobulinemia. Benign intermittent proteinuria can be found postprandially, after exercise or in cases of intense stress, while permanent proteinuria can be seen in glomerular lesions, pyelonephritis, tumors, myelomas, leishmaniasis (Ciaramella, and Corona, 2003). In this syndrome, the clinical manifestations of some patients such as pollakiuria, abdominal pain, stranguria and hematuria oriented diagnosis towards obstructive uropathy or renal tumor. The signs of uremia induced vomiting, dehydration, hypothermia and severe depression. The urinary bladder was distended and painful on palpation, the urinary catheter could not be easily placed. In the case of renal tumors, an increase in abdominal volume and persistent hematuria were observed.

Conventional radiological examination provides the most relevant information in renal colic syndrome and hematuria, consecutive to the presence of stones in the renal pelvis, urinary bladder(Figure 2A), ureters or urethraor in the case of hydronephrosis. In renal tumors, radiological chest examination may detect metastatic disease (Baeet al., 2007).Renal biopsy is mandatory for histological examination based on which a definitive diagnosis is established. In the urinary sediment, neoplastic cells can be evidenced (Bennett, 2004). The use of contrast substances evidences the topography of the kidneys and urinary tract (Figure 2B), and radiolucent urocystoliths. Ultrasonographic examination is recommended to evidence inflammatory lesions, radiolucent urocystoliths, the presence of tumors or hydronephrosis, and in the case of cardiac arrhythmias, laboratory examination is performed to determine the potassium value (Gennari and Segal, 2002).

Contrast-enhanced radiological examination was relevantin the case of traumas resulting in urinary retention with urinary bladder distension and the formation of a "bladder globe" (Figure 3A) or in uroperitoneum (Figure 3B).

In patients diagnosed with kidney failure, a reduction of the renal filtration capacity occurred, which clinically manifested by polydipsia-polyuria syndrome. The reduced filtration capacity determined an abnormal increase in the plasma urea and creatinine concentrations. Azotemia is not a pathognomonic sign of renal failure, being also found in prerenal disorders: dehydration, heart failure, protein-rich foods, gastrointestinal hemorrhage, cachexia, as well as in postrenal disorders such as urinary tract rupture or 

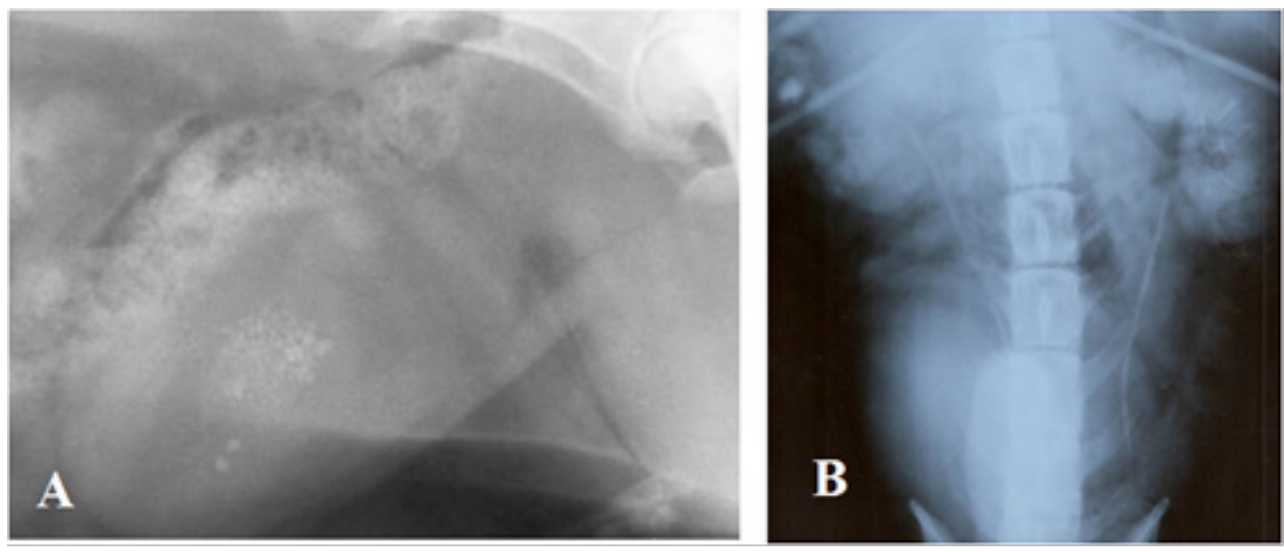

Figure 2. Urinary bladder stones -latero-lateral view $(65 \mathrm{Kv}, 10 \mathrm{~mA})$

(A); Intravenous urography with Optiray 350, ventro-dorsal view, at 15 minutes (65Kv, 10mA) (B)
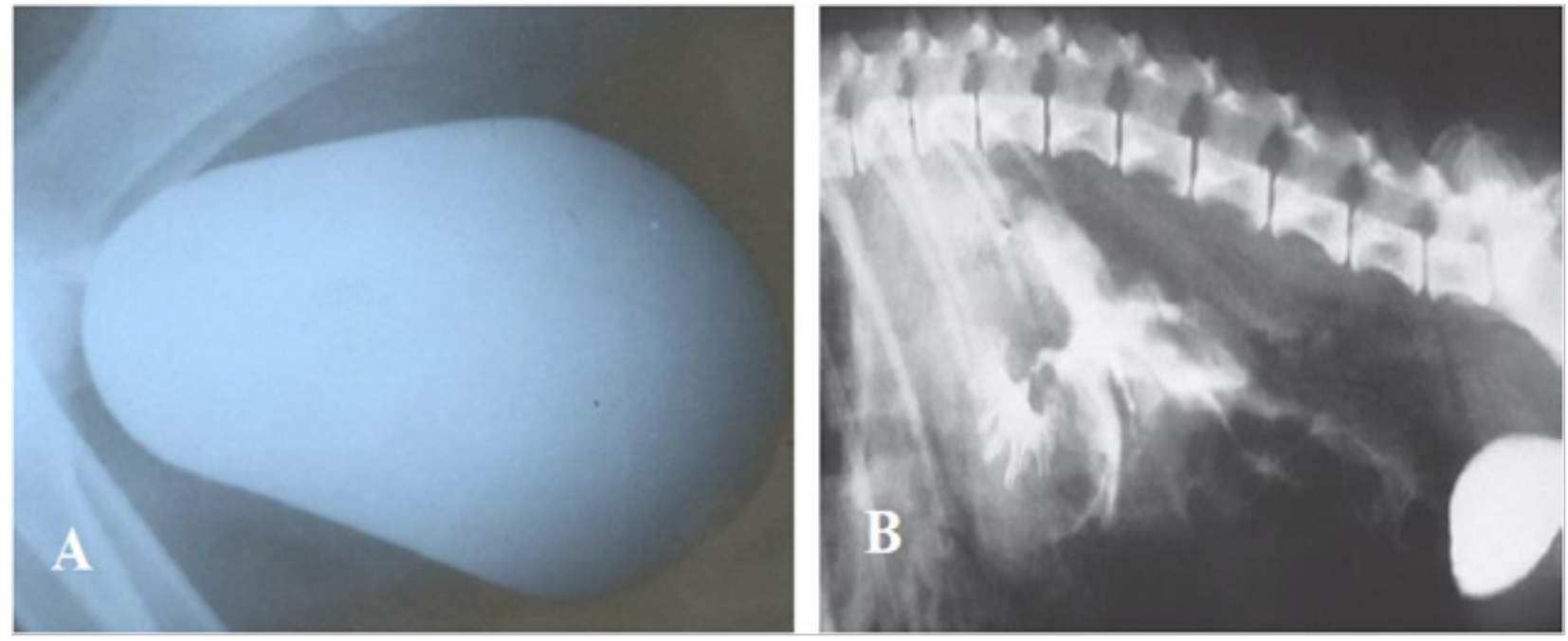

Figure3. Contrast radiography- moderate bladder globe, latero-lateral view, at 15 minutes $(65 \mathrm{Kv}, 10 \mathrm{~mA})(\mathrm{A})$; Uroperitoneum in a dog injured by a car (after Chew et al., 2011) (B)

urinary tract obstruction. In acute renal failure, sudden renal parenchymal injury clinically induced manifestations of anorexia, depression, dehydration, vomiting or diarrhea, oliguria (Merck Manual, 2014). In chronic renal failure, clinical manifestations were insidious for months, before becoming obvious. The disease invariably evolved progressively and irreversibly. Most frequently, chronic renal failure manifested as a systemic disease, associated with flank pain and vomiting. As the disease progressed, symptoms such as anorexia, weight loss, dehydration, oral ulcerations occurred. Laboratory examination in renal failure was conclusive. The determination of the urinary protein/creatinine ratio is mandatory, along with urinary albumin specific tests. Electrolyte homeostasis changes are frequently found. Radiographic and ultrasonographic images evidence small irregular kidneys or enlarged kidneys in patients with neoplasms. Urinalysis evidences renal epithelial cells, hemoglobinuria, urinary cylinders (Bartges, 2012).

Ultrasonographic examination is relevant in chronic renal failure, urinary retention, traumas, in topographic changes, dimensional and structural changes of the kidneys, in the case of renal calculosis, in urinary tract infections and in the case of tumor formations (Figure 4) (Kealy and McAllister, 2000). 


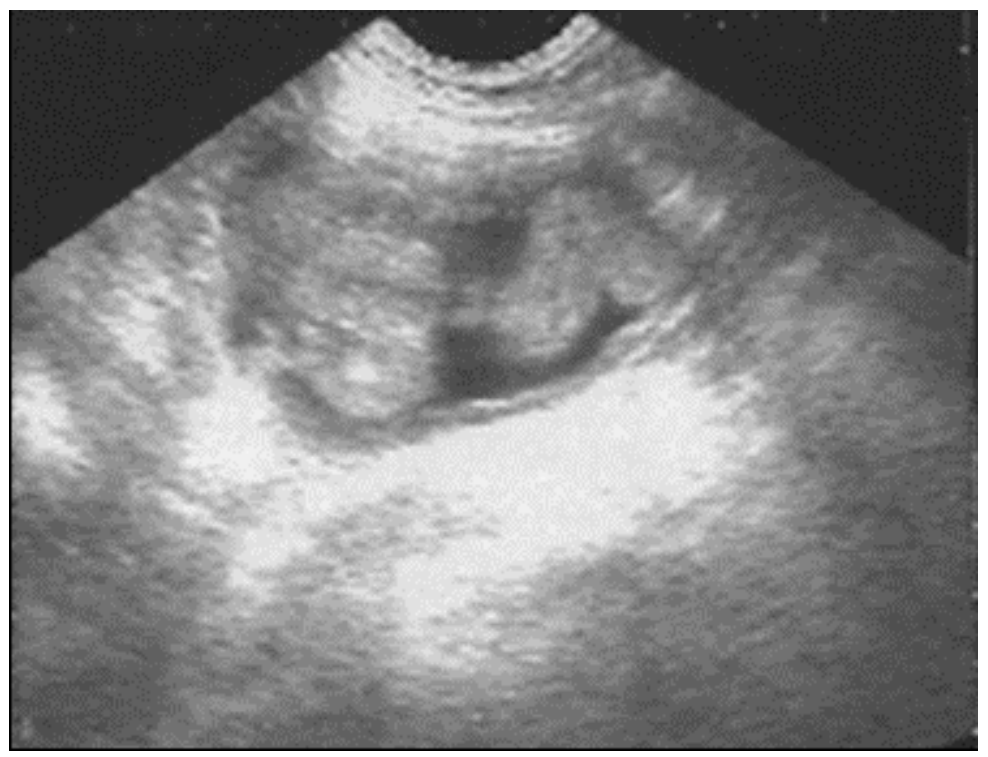

Figure 4. Urinary bladder ultrasound, a large hyperechogenic mass developed from the urinary bladder wall

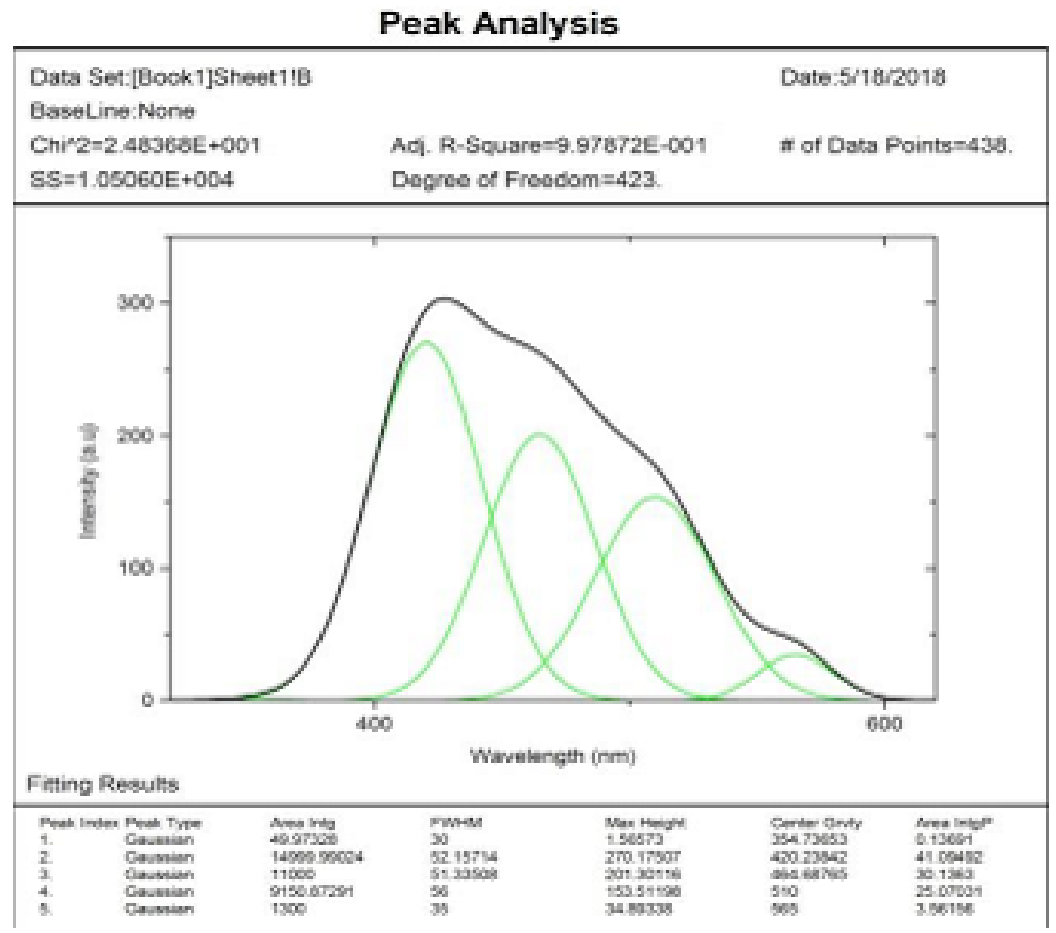

Figure 5. Deconvolution of the emission spectrum of a urine sample taken from a dog suspected of diabetes

Glomerular disease induced chronic renal failure, frequently associated with hyperadrenocorticism and diabetes mellitus. It clinically manifested by ascites, dyspnea, peripheral edema, clinical manifestations included in nephrotic syndrome. Laboratory examination revealed in- creased serum urea, creatinine values and high phosphorus concentrations. Renal biopsy was required to establish the type of disease: glomerular amyloidosis, membranous or proliferative glomerulitis (Harley and Langston, 2012). 

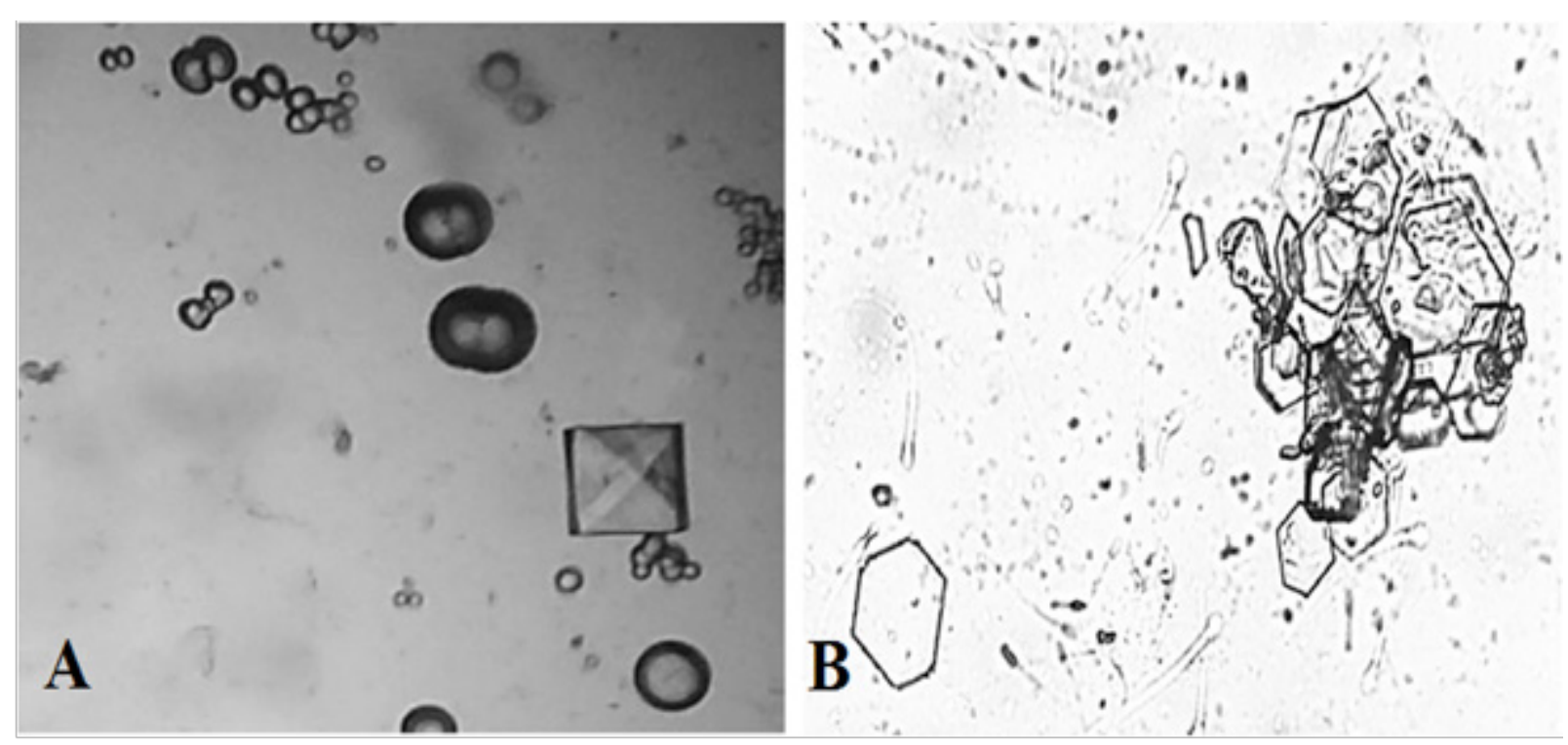

Figure 6. Unorganized mineral urinary sediment - calcium carbonates and oxalates (A); Unorganized organic urinary sediment -cystine crystals (B)

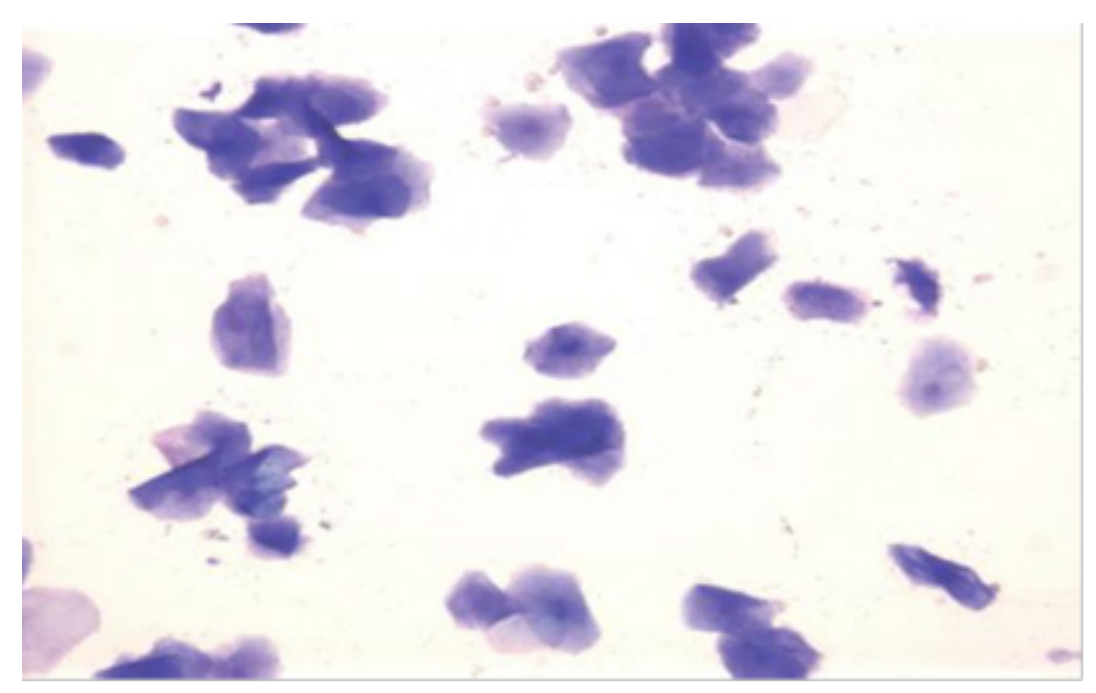

Figure 7. Evidencing of keratinized vaginal cells without a nucleus

Patients with the renal glucose thresholdexceeding the normal value of $180 \mathrm{mg} / \mathrm{dl}$, associated with glycosuriawere suspected of having diabetes mellitus. In these patients, one of the exams performed was spectrofluorimetric analysis (Figure 5). For the interpretation of the results, in the literature, an attribution of the emission bands obtained was first performed, followed by the Gaussian fitting of the spectra obtained (Olar et al.,2017; Olar et al. 2018).This technique can identify the urinary fluororophores whose concentration can significantly increase in diabetic comparatively with non-diabetic animals (Olar et al., 2017).

Cytological examination is particularly important in establishing the stages of the sexual cycle of the bitch and in the diagnosis of genitourinary disorders (Zanghì et al., 2007). In the females studied during the estrus period, vaginal smear was also performed. The microscopic examination of the urinary sediment was recommended in all situations where the presence of a genitourinary disease was suspected and had the value of a real histological. Calcium carbonate crystals 
have a circular or a ladyfinger form with some radial striations, whereas calcium oxalate crystals have a characteristic octahedral form and a similar appearance to a closed envelope (Figure 6A). The oxaluria can be evidenced in all glucose metabolism disorders, especially in diabetesandhas a pathological significance in dogs. The cysteine crystals are evidenced in the nonorganized urinary sediment, have an octagonal or hexagonal aspect (Figure 6B), and their presence can lead to bladder stone formation(Hesse et al., 2016).The presence of erythrocytes in the urine of female patients did not always have a pathological significance, because it could also be the result of estrus hemorrhage (Figure 7). The presence of keratinized vaginal cells without a nucleus in a proportion of over $50 \%$ in the vaginal smear showed the fact that the female was during the estrus period (Antonov et al., 2014).

\section{Conclusion}

Our study investigated the relevance and limitations of each paraclinical examination in establishing a certitude diagnosis in the pathology of the dog's urinary system. Therefore, in the renal colic syndrome and hematuria the following paraclinical exams are relevant: the conventional and contrast-enhanced radiological examination together with the echography and the urinalysis. In renal insufficiency a major importance is accorded to the plasma biochemical analysis. The echography and the conventional radiological examination can provide some supplementary information about this disease. The urine spectrofluorimetric analysis is relevant inthe study of diabetes mellitusas the levels of urinary fluorophores can increase significantly in diabetes dogs when compared to non-diabetic dogs. In the case of some renal tumors and glomerular disease the biopsy remains mandatory.In the genitourinary pathology, the microscopic examination of urine sediment has the value of a true histological investigation. The cytological exam identifies the dog heat cycle stages and complete the diagnosis. Therefore, the investigation of urinary disorders in dogs should include the following stages: a detailed anamnesis of the case, a complete clinical exam and a differential use of paraclinical tests according to the established clinical diagnosis in order to take some rational interventional decisions.
Acknowledgments. This research did not receive any specific grant from funding agencies in the public, commercial, or not-for-profit sectors.

\section{References}

1. Antonov AL, Dineva JD, Georgiev PI (2014). Dynamics of vaginal $\mathrm{pH}$ in the bitch during proestrus and Estrus. Animal and Veterinary Sciences, 2(4): 101-104.

2. Bae IH, Kim Y, Pakhrin B, You MH, Hwang CY, Kim JH, Kim DY (2007). Genitourinary rhabdomyosarcoma with systemic metastasis in a young dog. Vet. Pathol., 44(4):518-20.

3. Barr F, O'Brien R (2009). Manual of Canine and Feline Abdominal Imaging, BSAVA, Gloucester.

4. Bartges JW (2012). Chronic Kidney Diseasein DogsandCats. Veterinary Clinics of North America: Small Animal Practice, 42:669-692.

5. Bennett $F$ (2004). Unilateral renal cell carcinoma in a Labrador retriever. Can Vet J, 45(10): 860-862.

6. Ciaramella P, Corona M (2003). Canine leishmaniasis: clinical and diagnostic aspects. Compendium, 25:358-68.

7. Chew DJ, Dibartola P, Schenck A (2011). Canine and Feline Nephrology and Urology, Second Edition. Saunders.

8. Froes TR et al. (2007). Ultrasonography and Color Doppler Investigation of Transitional Cell Carcinoma of the Bladder in Dogs, Arquivo Brasileiro de MedicinaVeterinaria a Zootecnia, 59(6):1400-1407.

9. Gennari FJ, Segal AS (2002). Hyperkalemia: An adaptive response in chronic renal insufficiency. Kidney International, 62(1):1-9.

10. Hann CM et al. (1994). Practical Guide to Diagnostic Imaging:Radiology and Ultrasonography American Veterinary Publications, The University of Michigan, Michigan.

11. Hanson JA et al. ( 2001). Survival in recipients of marginal cadaveric donor kidneys compared with other recipients and wait-listed transplant candidates. J Am Soc Nephrol, 12(3):589-97.

12. Harley L, Langston C, (2012). Proteinuria in dogs and cats. Can Vet J, 53(6): 631-638.

13. Herbert F (2006). Guide pratique de médicine interne canine et féline. $2^{\mathrm{e}}$ edition. Ed.Med'Com.

14. Hesse A, Hoffmann J, Orzekowsky H, Neiger R (2016). Canine cystineurolithiasis: A review of 1760 submissions over 35 years (1979-2013).Can Vet J, 57(3): 277-281.

15. Kaneko JJ, Harvey JW, Bruss ML (2008). Clinical Biochemistry of Domestic Animals, sixth edition. Elsevier.

16. Kealy KJ (2005). Diagnostic Radiology and Ultrasonography of the Dog and Cat, Elsevier Saunders.

17. Kealy KJ, McAllister H (2000). Diagnostic Radiology and Ultrasonography of the Dog and Cat, $3^{\text {rd }}$ Edition, Elsevier Saunders.

18. Lulich JP, Berent AC, Adams LG, Westropp JL, Bartges JW Osborne CA (2016). ACVIM Small AnimalConsensus 
Recommendations on the Treatment and Prevention of Uroliths in Dogs and Cats. J Vet Intern Med, 30:1564-1574.

19. Merck (2014). Manualul Merck de Medicină Veterinară, Ed. Callisti, București.

20. Medaille C, Briend-Marchal A (2008). Guide pratique des analyses biologiques vétérinaires. Ed. Med'Com.

21. Muñoz Rascón P, Morgaz Rodriguez J, Galán Rodriguez Alba (2015). Manual clinicodelperro y el gato, 2. Edition, Elsevier Espana, S.L.U.

22. Olar LE, Ciobanu DM, Matei F, Papuc I (2018). The Assessment of Fluorophores Advanced Glycation End Products-to-Kynurenine Ratio in Healthy and Diabetic Rats and Humans, Studia UBB Chemia, LXIII (1): 37-53.

23. Olar LE, Stefan R, Catioiu A, Papuc I (2017). Evaluation of Urinary Tryptophan Metabolite Levels in Non-diabetic Compared to Diabetic Rats, Bulletin UASVM Veterinary Medicine, 74:173-178.

24. Sato AF, Solano M (2004). Ultrasonographic Findings in Abdominal Mast Cell Disease: A Retrospective Study of 19 Patients. Veterinary Radiology Ultrasound, 45:51-57.

25. Schelling CG et al (1988). Ultrasonic Detection of Splenic Necrosis in the Dog. Three Case Reports of Splenic
Necrosis Secondary to Infraction.Veterinary Radiology, 29:227.

26. Šteffeková Z, Birková A, Baranová D, Mareková M (2015). Pilot Study of Canine Urine Analysis Using Fluorescent Fingerprint. Spectroscopy Letters, 489(6):447-453

27. Thrall DE, Robertson DI (2010). Atlas of Normal Radiographic Anatomy and Anatomic Variants in the Dog and Cat, Elsevier, USA.

28. Vaden S, Knoll J, Smith FWK, Tilley LP (2009). Blackwell's five minute veterinary consult: Laboratory tests and diagnostic procedures canine \& feline. Wiley-Blackwell.

29. Yanagisawa K, Makita Z, Shiroshita K, Ueda T, Fusegawa T, Kuwajima S, Takeuchi M, Koike T (1998). Specific fluorescence assay for advanced glycation end products in blood and urine of diabetic patients. Metabolism, 47(11):1348-1353.

30. Zanghì A, Catone G, Marino G, Quartuccio M, Nicòtina PA (2007). Endometrial Polypoid Adenomyomatosis in a Bitch with Ovarian Granulosa Cell Tumour and Pyometra. Journal of Comparative Pathology, 136(1):83-86. 